\title{
Tubeimoside I attenuates inflammation and oxidative damage in a mice model of $\mathbf{P M}_{2.5}$-induced pulmonary injury
}

\author{
JIN-BO ZHANG ${ }^{1}$, LEI ZHANG ${ }^{2}$, SHI-QING LI ${ }^{3}$, AI-HUA HOU ${ }^{4}$, WEI-CHAO LIU ${ }^{1}$ and LING-LING DAI ${ }^{4}$ \\ ${ }^{1}$ Center of Preventive Treatment of Disease; Departments of ${ }^{2}$ Heart Disease, ${ }^{3}$ Encephalopathy and \\ ${ }^{4}$ Oncology, Yantai Hospital of Traditional Chinese Medicine, Yantai, Shandong 264000, P.R. China
}

Received November 25, 2016; Accepted October 20, 2017

DOI: $10.3892 /$ etm.2017.5597

\begin{abstract}
In the present study, the effects of tubeimoside I (TBMS1) on particulate matter $<2.5 \mu \mathrm{m}$ in diameter $\left(\mathrm{PM}_{2.5}\right)$-induced pulmonary injury and its mechanisms of action were investigated. Male BALB/c mice were randomly assigned into five groups ( $\mathrm{n}=10 /$ group): Control, $\mathrm{PM}_{2.5}$, $\mathrm{PM}_{2.5}+$ TBMS1 $45 \mathrm{mg} / \mathrm{kg}, \mathrm{PM}_{2.5}+$ TBMS1 $90 \mathrm{mg} / \mathrm{kg}$ and $\mathrm{PM}_{2.5}+$ TBMS1 $180 \mathrm{mg} / \mathrm{kg}$. The dose of the $\mathrm{PM}_{2.5}$ suspension administered to the mice was $40 \mathrm{mg} / \mathrm{kg}$ via nasal instillation. The $\mathrm{PM}_{2.5}+$ TBMS1 groups received TBMS1 daily orally for 21 consecutive days, while the mice in the control and $\mathrm{PM}_{2.5}$ groups received equivalent volumes of PBS. Subsequently, lactic dehydrogenase, acid phosphatase, alkaline phosphatase, albumin, tumor necrosis factor- $\alpha$ and interleukin- 6 protein levels in bronchoalveolar lavage fluid were determined. Oxidative stress was evaluated by detecting the protein levels of malondialdehyde, superoxide dismutase and inducible nitric oxide synthase, and the level of nitric oxide in lung tissue. Lastly, histopathological images of lung sections were obtained to observe changes in the lung tissue with treatment. The results indicated that exposure to $\mathrm{PM}_{2.5}$ induced pathological pulmonary changes, and biofilm and parenchymal cell damage, and promoted inflammation and oxidative stress. Treatment with TBMS1 attenuated the development of $\mathrm{PM}_{2.5}$-induced pulmonary injury. Its mechanisms of action were associated with reducing cytotoxic effects, levels of inflammatory mediators and oxidative damage. In conclusion, the results of the present study indicate that TBMS1 is a potential therapeutic drug for treating $\mathrm{PM}_{2.5}$-induced pulmonary injury.
\end{abstract}

Correspondence to: Dr Jin-Bo Zhang, Center of Preventive Treatment of Disease, Yantai Hospital of Traditional Chinese Medicine, 39 Xingfu Road, Yantai, Shandong 264000, P.R. China E-mail: zhangjinboo@hotmail.com

Key words: tubeimoside I, inflammation, oxidative damage, particle matter $<2.5 \mu \mathrm{m}$ in diameter, pulmonary injury

\section{Introduction}

Airborne particulate matter (PM) is known to contribute significantly to diseases (1-3). PM with an aerodynamic diameter $<2.5 \mu \mathrm{m}\left(\mathrm{PM}_{2.5}\right)$ is the primary PM pollutant. Sources of $\mathrm{PM}_{2.5}$ include toxic organic compounds, heavy metals, the burning of plant material and forest fires (4). $\mathrm{PM}_{2.5}$ is easily inhaled into the airway and deposited in lung alveoli, where the toxic particles may affect pulmonary structures and functions. A number of studies have documented that $\mathrm{PM}_{2.5}$ exposure increases the risk of pulmonary diseases and lung cancer $(5,6)$. Chronic obstructive pulmonary disease (COPD) is a type of pulmonary disease that involves chronic inflammation of the peripheral airways and lung parenchyma, and results in edema, mucociliary dysfunction and hypoxic vasoconstriction of pulmonary arterioles (7). Haze is the most important etiological factor in the development and progression of COPD (8).

$\mathrm{PM}_{2.5}$ contains multiple harmful chemicals that lead to inflammatory responses and oxidative stress in the lungs $(9,10)$. Marker enzymes are released in the lung lavage fluid, including lactic dehydrogenase (LDH), acid phosphatase (ACP), alkaline phosphatase (AKP) and albumin (ALB) that indicate damage to the lung cell integrity $(11,12)$. Inflammation is the initial response following pulmonary injury and it induces the production of reactive oxygen species (ROS) in the lungs, the generation of ROS results in lipid peroxidation. Superoxide dismutase (SOD), malondialdehyde (MDA), inducible nitric oxide synthase (iNOS) and nitric oxide (NO) are oxidative stress associated indicators (13). Inhaled toxic agents stimulate the generation of ROS/reactive nitrogen species, which in turn stimulate inflammatory cells to release inflammatory mediators, including tumor necrosis factor- $\alpha$ (TNF- $\alpha$ ), interleukin-6 (IL-6) and IL-1 $\beta$ (14). Therefore, pharmaceutical agents with anti-inflammatory and anti-oxidant properties may be beneficial to individuals with $\mathrm{PM}_{2.5}$-induced pulmonary injury.

Tubeimoside I (TBMS1) is a natural compound isolated from the Chinese medicinal herb Bolbostemma paniculatum (Maxim.) Franquet (Cucurbitaceae). It has been reported that TBMS1 exhibits potent anti-apoptotic, anti-inflammatory and anti-oxidative effects (15-17). These studies suggested that TBMS1 possesses features that could protect against $\mathrm{PM}_{2.5}$-induced pulmonary injury. The aim of the present study 
was to investigate the effect of TBMS1 on pulmonary injury in a mouse model. The underlying regulatory mechanisms associated with the potential anti-inflammatory and anti-oxidant effects of TBMS1 were also investigated.

\section{Materials and methods}

Reagent. TBMS1 (purity $>98 \%$; purified by high-performance liquid chromatography) was purchased from Tianjin Chase Sun Pharmaceutical Co., Ltd. (Tianjin, China). It was dissolved in PBS and stored at $-20^{\circ} \mathrm{C}$.

Animals. A total of 50 male BALB/c mice (8 weeks old, weighing 22-25 g) were obtained from the Experimental Animal Center of Suzhou Aiermaite Technology Co., Ltd. (Suzhou, China; specific pathogen-free grade; certificate no. SCXK20140007). All animals were housed under specific pathogen-free conditions with a 12-h light/dark cycle at $22-24^{\circ} \mathrm{C}, 50 \pm 10 \%$ relative humidity and free access to water and food. All experimental protocols were approved by the Committee on the Ethics of Animal Experiments of Yantai Hospital of Traditional Chinese Medicine (Shandong, China).

Experimental procedure. Male BALB/c mice were randomly assigned to five groups ( $\mathrm{n}=10$ ): Control, $\mathrm{PM}_{2.5}, \mathrm{PM}_{2.5}+\mathrm{TBMS1}$ $45 \mathrm{mg} / \mathrm{kg}, \mathrm{PM}_{2.5}+$ TBMS1 $90 \mathrm{mg} / \mathrm{kg}$ and $\mathrm{PM}_{2.5}+\mathrm{TBMS} 1$ $180 \mathrm{mg} / \mathrm{kg}$. All PM samples used during these studies were collected from Yantai, China using a PM2.5 high volume sampler system (TE-6070V-2.5-HVS; Tisch Environmental Inc., Village of Cleves, OH, USA). The samples collected in the quartz fiber filters were then packed in clean aluminum foil and stored at $-20^{\circ} \mathrm{C}$ until analyses were performed. The dose of the $\mathrm{PM}_{2.5}$ suspension was $40 \mathrm{mg} / \mathrm{kg}$ and was administered to mice via nasal instillation on days 7,14 and 21 . The control mice were treated with equivalent volumes $(0.2 \mathrm{ml})$ of physiological saline. For 21 consecutive days the $\mathrm{PM}_{2.5}+$ TBMS1 groups received TBMS1 orally daily, while the mice in the control and $\mathrm{PM}_{2.5}$ groups were administered equivalent volumes $(0.2 \mathrm{ml})$ of PBS.

Bronchoalveolar lavage fluid (BALF) collection and biochemical analysis. Following anesthesia by intraperintoneal injection of pentobarbital sodium $(200 \mathrm{mg} / \mathrm{kg}$ body weight), the tracheas were cannulated and the lungs were gently washed with $1 \mathrm{ml}$ PBS. The BALFs were collected immediately after sacrificing and the lungs were excised for further analysis. BALF samples were centrifuged at $1,000 \mathrm{x}$ for $10 \mathrm{~min}$ at $4^{\circ} \mathrm{C}$ and the supernatant was collected. The protein levels of LDH (cat. no. A020-1), ACP (cat. no. A060-1), AKP (cat. no. A059-1), ALB (cat. no. A028-1), TNF- $\alpha$ (cat. no. H052) and IL-6 (cat. no. H007) in the BALF were measured by ELISA kits (Nanjing Jiancheng Bioengineering Institute, Nanjing, China), according to the manufacturer's protocol.

Biochemical analysis of antioxidant status. The lungs were excised and homogenized in PBS on ice to make the $10 \%$ pulmonary homogenate. The activity of SOD (cat. no. A001-3), the level of MDA (cat. no. A003-4) and iNOS (cat. no. A014-1), and the concentration of NO (cat. no. A013-1) in the lung homogenates were measured by ELISA kits (Nanjing Jiancheng Bioengineering Institute), according to the manufacturer's protocol.

Histopathological evaluation. The lungs were fixed in $10 \%$ neutral formalin, embedded in paraffin and cut into 5 - $\mu \mathrm{m}$-thick sections. The samples were then stained with hematoxylin and eosin and examined using a light microscope at room temperature (DP73; Olympus Corporation, Tokyo, Japan) at a magnification of $\mathrm{x} 200$.

Statistical analysis. All data are presented as the mean \pm standard deviation. SPSS software (version 17.0; SPSS, Inc., Chicago, IL, USA) was used to perform all statistical analyses. Statistical comparisons of multiple groups were performed by one-way analysis of variance with the Bonferroni post hoc test. $\mathrm{P}<0.05$ was considered to indicate a statistically significant difference.

\section{Results}

TBMS1 reduces $P M_{2.5}$-induced pulmonary biofilm and parenchymal cell damage. LDH, ACP, AKP and ALB in BALF were assessed in order to define the level of damage to the pulmonary biofilm and parenchymal cells. The protein levels of LDH, ACP, AKP and ALB in the $\mathrm{PM}_{2.5}$ group (LDH,

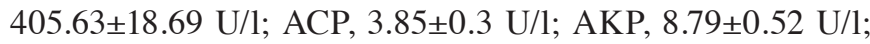
ALB, $198.24 \pm 17.39 \mathrm{mg} / \mathrm{l})$ were significantly increased compared with the control group (LDH, 112.97 $\pm 8.56 \mathrm{U} / \mathrm{l}$; ACP, $1.64 \pm 0.14 \mathrm{U} / \mathrm{l}$; AKP, 4.65 $\pm 0.35 \mathrm{U} / \mathrm{l}$; ALB, 64.32 $\pm 6.21 \mathrm{mg} / \mathrm{l}$ ) (all $\mathrm{P}<0.05$; Fig. 1). By contrast, TBMS1 treatment significantly reduced the levels of LDH, ACP, AKP and ALB compared with the $\mathrm{PM}_{2.5}$ group (all $\left.\mathrm{P}<0.05\right)$.

TBMS1 decreases $P M_{2.5}$-induced pulmonary inflammation. To analyze the effects of TBMS1 treatment on $\mathrm{PM}_{2.5}$-induced proinflammatory cytokine release, the protein levels of TNF- $\alpha$ and IL- 6 in BALF were analyzed by ELISA. As shown in Fig. 2, the levels of TNF- $\alpha$ and IL-6 in BALF were significantly increased in the $\mathrm{PM}_{2.5}$ group (TNF- $\alpha, 212.51 \pm 17.93$ $\mathrm{pg} / \mathrm{ml}$; IL-6, 162.31 $\pm 9.43 \mathrm{pg} / \mathrm{ml})$ compared with the control group (TNF- $\alpha, 15.42 \pm 2.73 \mathrm{pg} / \mathrm{ml}$; IL-6, 88.69 $\pm 5.71 \mathrm{pg} / \mathrm{ml}$ ) (both $\mathrm{P}<0.05)$. Treatment with TBMS1 significantly reduced the production of these cytokines (all $\mathrm{P}<0.05$ ).

TBMS1 decreases $P M_{2.5}$-induced pulmonary oxidative stress. To analyze the effects of TBMS1 on oxidative stress induced by $\mathrm{PM}_{2.5}$, the levels of MDA, SOD, NO and iNOS from the lung tissues of mice were analyzed. As shown in Fig. 3, the levels of MDA, NO and iNOS in the $\mathrm{PM}_{2.5}$ group (MDA, $1.79 \pm 0.19 \mathrm{nmol} / \mathrm{mg}$; NO, $13.71 \pm 0.62 \mu \mathrm{mol} / \mathrm{g}$; iNOS, $0.89 \pm 0.08 \mathrm{U} / \mathrm{mg}$ ) were significantly increased compared with the control group (MDA, $0.72 \pm 0.08 \mathrm{nmol} / \mathrm{mg}$; NO, $4.21 \pm 0.49 \mu \mathrm{mol} / \mathrm{g}$; iNOS, $0.32 \pm 0.04 \mathrm{U} / \mathrm{mg})($ all $\mathrm{P}<0.05)$. The level of SOD in the $\mathrm{PM}_{2.5}$ group (23.24 $\left.\pm 3.62 \mathrm{U} / \mathrm{mg}\right)$ was significantly decreased compared with the control group $(86.89 \pm 6.89 \mathrm{U} / \mathrm{mg})(\mathrm{P}<0.05)$. Treatment with TBMS1 significantly decreased the levels of MDA, NO and iNOS, and significantly increased the SOD level (all $\mathrm{P}<0.05)$. 

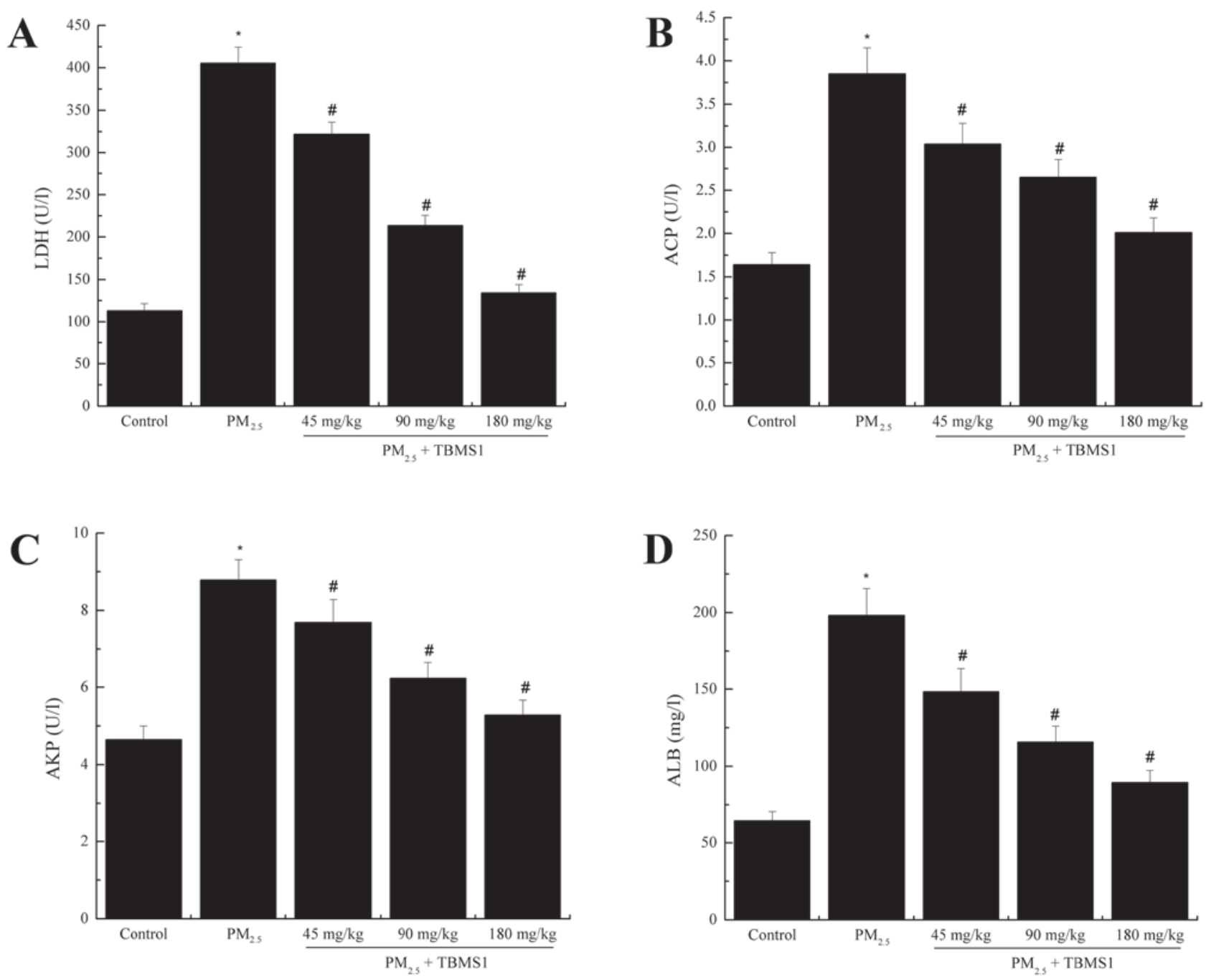

Figure 1. TBMS1 reduces $\mathrm{PM}_{2.5}$-induced pulmonary biofilm and parenchymal cell damage. Protein levels of (A) LDH, (B) ACP, (C) AKP and (D) ALB were evaluated. Data are presented as the mean \pm standard deviation. ${ }^{~} \mathrm{P}<0.05$ vs. control group; ${ }^{*} \mathrm{P}<0.05$ vs. $\mathrm{PM}_{2.5}$ group. TBMS1, Tubeimoside I; $\mathrm{PM}{ }_{2.5}$, particulate matter $<2.5 \mu \mathrm{m}$ in diameter; LDH, lactic dehydrogenase; ACP, acid phosphatase; AKP, alkaline phosphatase; ALB, albumin.
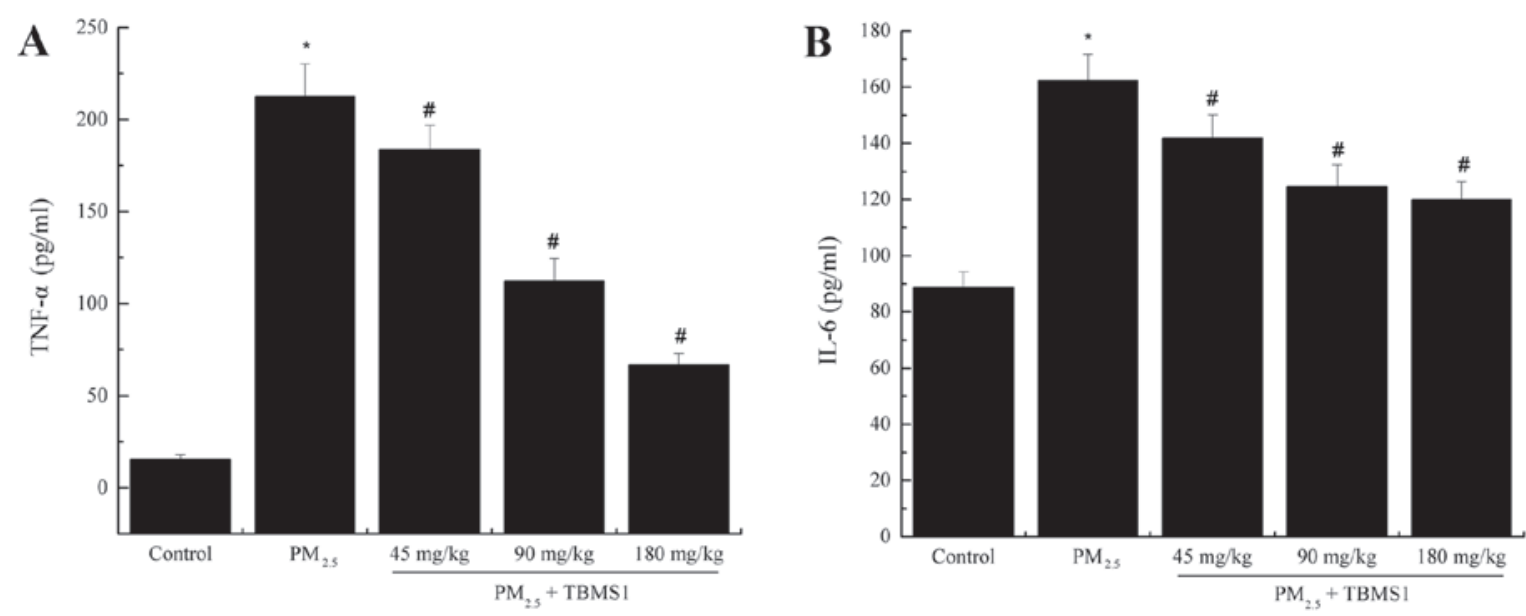

Figure 2. TBMS1 decreases $\mathrm{PM}_{2.5}$-induced pulmonary inflammation. Protein levels of (A) TNF- $\alpha$ and (B) IL-6 were evaluated. Data are presented as the mean \pm standard deviation. ${ }^{~} \mathrm{P}<0.05$ vs. control group; ${ }^{~} \mathrm{P}<0.05$ vs. $\mathrm{PM}_{25}$ group. TBMS1, Tubeimoside I; $\mathrm{PM}_{25}$, particulate matter $<2.5 \mu \mathrm{m}$ in diameter; $\mathrm{TNF}$, tumor necrosis factor; IL, interleukin. 

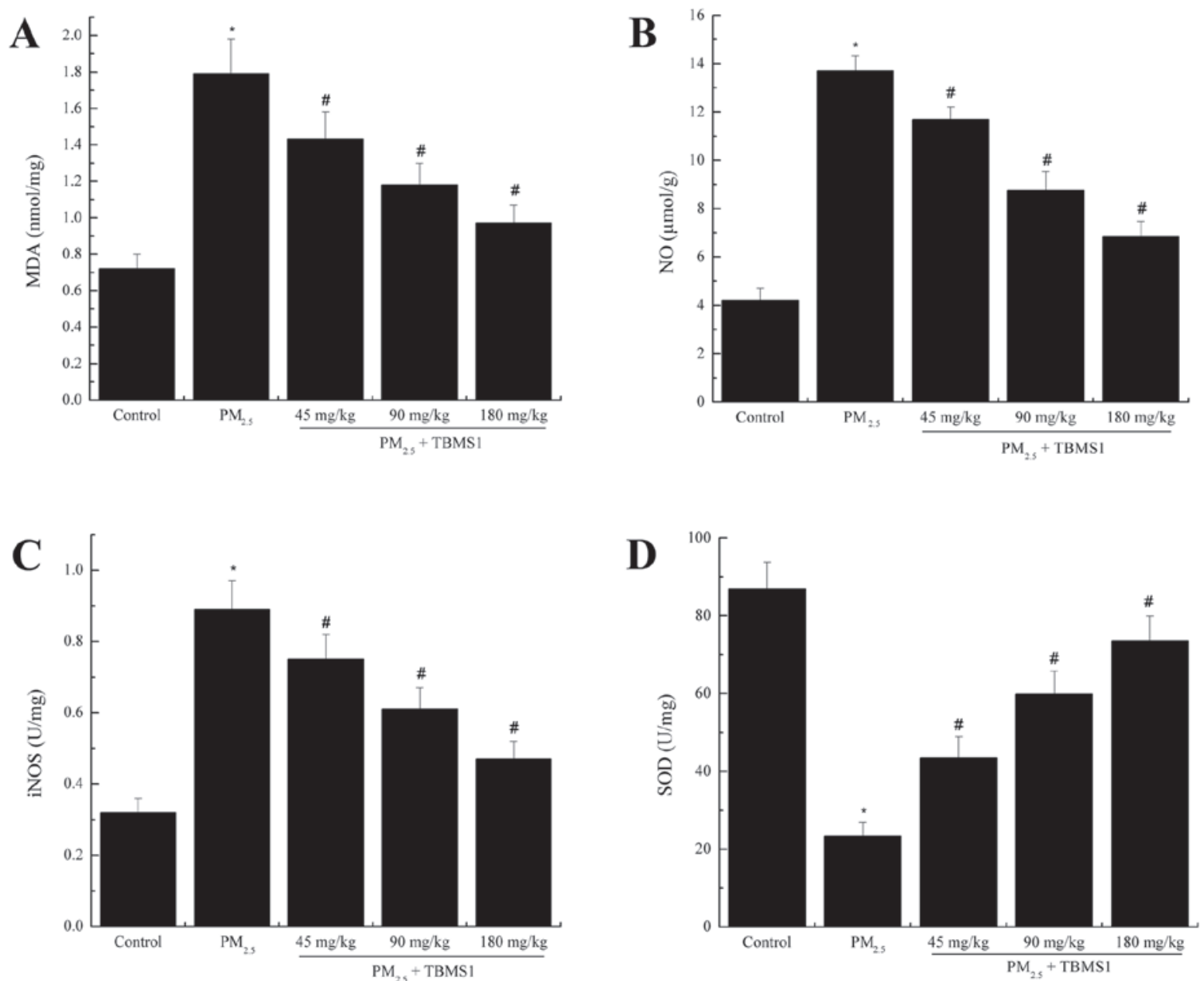

Figure 3. TBMS1 decreases $\mathrm{PM}_{2.5}$-induced pulmonary oxidative stress. The levels of (A) MDA, (B) NO, (C) iNOS and (D) SOD. Data are presented as the mean \pm standard deviation. "P $<0.05$ vs. control group; ${ }^{\prime} \mathrm{P}<0.05$ vs. $\mathrm{PM}_{2.5}$ group. TBMS1, Tubeimoside I; $\mathrm{PM}_{2.5}$, particulate matter $<2.5 \mu \mathrm{m}$ in diameter; MDA, malondialdehyde; NO, nitric oxide; iNOS, inducible NO synthase; SOD, superoxide dismutase.

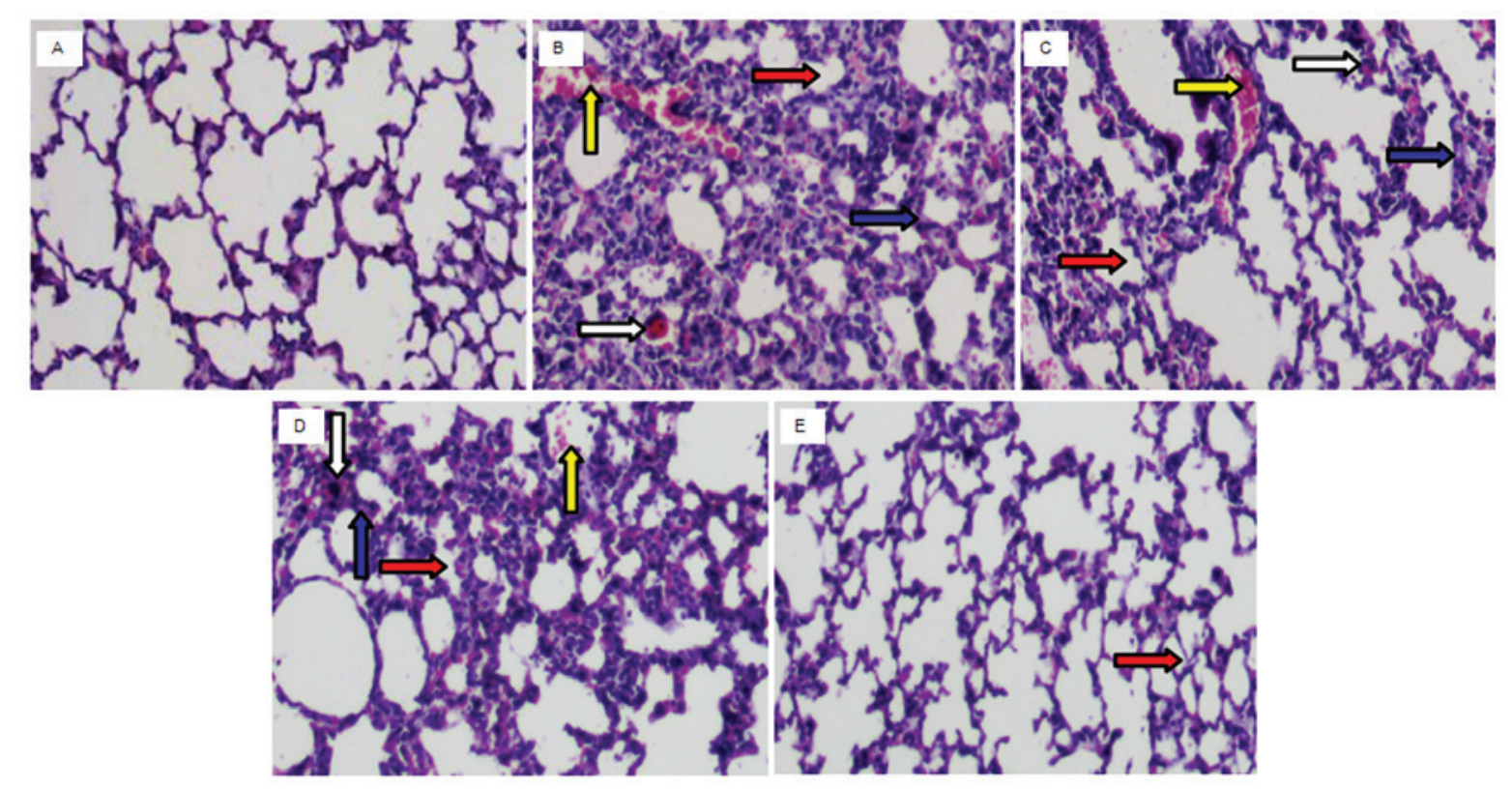

Figure 4. TBMS1 ameliorates $\mathrm{PM}_{2.5}$-induced histological changes in the lung. Inflammatory cell infiltration, interstitial edema, alveolar space diminishment and hyperemia were observed in the control group. However, these alterations were markedly attenuated by TBMS1 administration. The white, blue, red and yellow arrows indicate sites of inflammatory cell infiltration, interstitial edema, alveolar space diminishment and hyperemia, respectively. (A) Control group. (B) $\mathrm{PM}_{2.5}$ group. (C) $\mathrm{PM}_{2.5}+$ TBMS1 $45 \mathrm{mg} / \mathrm{kg}$ group. (D) $\mathrm{PM}_{2.5}+$ TBMS1 $90 \mathrm{mg} / \mathrm{kg}$ group. (E) $\mathrm{PM}_{2.5}+$ TBMS1 $180 \mathrm{mg} / \mathrm{kg}$ group. Magnification, x200. TBMS1, Tubeimoside I; $\mathrm{PM}_{2.5}$, particulate matter $<2.5 \mu \mathrm{m}$ in diameter. 
congestion and hyperemia. However, these alterations were markedly attenuated by TBMS1 administration (Fig. 4C-E).

\section{Discussion}

Epidemiological studies have demonstrated that $\mathrm{PM}_{2.5}$ exposure correlates with increased incidence of respiratory diseases $(18,19)$. Short-term exposure to $\mathrm{PM}_{2.5}$ has been reported as associated with acute airway inflammation (20). In the present study, a mouse model was established to investigate the protective effects of TBMS1 against pulmonary injury induced by $\mathrm{PM}_{2.5}$. TBMS1 treatment significantly attenuated cytotoxic effects, reduced the levels of inflammatory cytokines and inhibited oxidative stress-induced damage.

The lungs are susceptible to infiltration by a wide variety of airborne particles. Damage to the lungs was observed in the histological sections and BALF samples. Lung injuries were observed in $\mathrm{PM}_{2.5}$-treated mice, including inflammatory cell infiltration, interstitial edema, alveolar wall thickening, congestion and hyperemia. $\mathrm{LDH}, \mathrm{ACP}, \mathrm{AKP}$ and ALB in the BALF reflected the level of damage to the pulmonary biofilm and parenchymal cells. In the $\mathrm{PM}_{2.5}$ group, it was identified that LDH, ACP, AKP and ALB protein levels were significantly elevated compared with the control group, which suggests that the pulmonary biofilm and parenchymal cells were damaged. This damage was significantly attenuated by TBMS1 treatment. These results indicate that TBMS1 may exhibit protective effects against $\mathrm{PM}_{25}$-induced pulmonary injury.

Inflammation is a fundamental host defense response to cellular and tissue injury. Following $\mathrm{PM}_{2.5}$ exposure, inflammatory responses are stimulated and numerous inflammatory cytokines are released from the lung parenchyma $(21,22)$. To investigate whether the protective effect of TBMS1 against $\mathrm{PM}_{2.5}$-induced pulmonary injury was associated with inflammation, TNF- $\alpha$ and IL- 6 levels were measured. These proinflammatory cytokines are known to be elevated in the BALF of lung disease patients (23). The present study revealed that TBMS1 treatment significantly decreased TNF- $\alpha$ and IL-6 protein in BALF. These results indicate that TBMS1 treatment may ameliorate $\mathrm{PM}_{2.5}$-induced damage by suppressing inflammation.

The association between pulmonary injury and oxidative stress was also investigated. PM can directly and indirectly generate ROS, and a previous study demonstrated that oxidative stress initiated by ROS caused adverse effects, as it activated cell apoptosis (24). MDA is the end-product of oxygen-derived free radicals and lipid oxidation, which is a marker of damage caused by ROS (25). SOD is an essential antioxidant enzyme in the body, which assists the reaction between free radicals and other chemicals to produce safe substances (26). The majority of NO is produced by iNOS, and excessive NO may cause oxidative damage and cytotoxicity $(27,28)$. In the present study, the levels of MDA, NO and iNOS were significantly increased, and the SOD level was significantly decreased, in the lung tissue homogenate of the $\mathrm{PM}_{2.5}$ group compared with the control group. TBMS1 treatment decreased the levels of MDA, NO and iNOS, and increased the SOD levels. These results indicate that TBMS1 treatment improved the antioxidant capacity and reduced oxidative lipid damage.

In conclusion, the results of the present study demonstrate that TBMS1 exhibits a protective effect against $\mathrm{PM}_{2.5}$-induced pulmonary injury. A possible explanation for this effect is the anti-inflammatory and antioxidant effects of TBMS1. On the basis of the present results, TBMS1 appears to be a promising therapeutic agent for the treatment of $\mathrm{PM}_{2.5}$-induced pulmonary injury.

\section{References}

1. Dvonch JT, Kannan S, Schulz AJ, Keeler GJ, Mentz G, House J, Benjamin A, Max P, Bard RL and Brook RD: Acute effects of ambient particulate matter on blood pressure differential effects across urban communities. Hypertension 53: 853-859, 2009.

2. Pelucchi C, Negri E, Gallus S, Boffetta P, Tramacere I and La Vecchia C: Long-term particulate matter exposure and mortality: A review of European epidemiological studies. BMC Public Health 9: 453, 2009.

3. Brook RD, Rajagopalan S, Pope CA III, Brook JR, Bhatnagar A, Diez-Roux AV, Holguin F, Hong Y, Luepker RV, Mittleman MA, et al: Particulate matter air pollution and cardiovascular disease: An update to the scientific statement from the American Heart Association. Circulation 121: 2331-2378, 2010.

4. Wan Q, Cui X, Shao J, Zhou F, Jia Y, Sun X, Zhao X, Chen Y, Diao J and Zhang L: Beijing ambient particle exposure accelerates atherosclerosis in ApoE knockout mice by upregulating visfatin expression. Cell Stress Chaperones 19: 715-724, 2014.

5. Vinikoor-Imler LC, Davis JA and Luben TJ: An ecologic analysis of county-level $\mathrm{PM}_{2.5}$ concentrations and lung cancer incidence and mortality. Int J Environ Res Public Health 8: 1865-1871, 2011.

6. Cao L, Geng H, Yao C, Zhao L, Duan P, Xuan Y and Li H: Investigation of chemical compositions of atmospheric fine particles during a wintertime haze episode in taiyuan city. China Environ Sci 34: 837-843, 2014.

7. Rabe KF, Hurd S, Anzueto A, Barnes PJ, Buist SA, Calverley P, Fukuchi Y, Jenkins C, Rodriguez-Roisin R, van Weel C and Zielinski J; Global Initiative for Chronic Obstructive Lung Disease: Global strategy for the diagnosis, management, and prevention of chronic obstructive pulmonary disease: GOLD executive summary. Am J Respir Crit Care Med 176: 532-555, 2007.

8. Van Winkle LS, Bein K, Anderson D, Pinkerton KE, Tablin F, Wilson D and Wexler AS: Biological dose response to PM2.5: Effect of particle extraction method on platelet and lung responses. Toxicol Sci 143: 349-359, 2015.

9. Barnes PJ: Chronic obstructive pulmonary disease. N Engl J Med 343: 269-280, 2000.

10. Vestbo J,Hurd SS,Agustí AG,Jones PW,VogelmeierC, Anzueto A, Barnes PJ, Fabbri LM, Martinez FJ, Nishimura M, et al: Global strategy for the diagnosis, management and prevention of chronic obstructive pulmonary disease: GOLD executive summary. Am J Respir Crit Care Med 187: 347-365, 2013.

11. Jia BS and Gao Y: Protective effect of trihexyphenidyl on hydrogen peroxide-induced oxidative damage in PC12 cells. Neurosci Lett 437: 50-54, 2008.

12. Rahman MF and Siddiqui MK: Biochemical effects of vepacide (from Azadirachta indica) on Wistar rats during subchronic exposure. Ecotoxicol Environ Saf 59: 332-339, 2004.

13. Rosanna DP and Salvatore C: Reactive oxygen species, inflammation and lung diseases. Curr Pharm Des 18: 3889-3900, 2012.

14. Tuder RM and Petrache I: Pathogenesis of chronic obstructive pulmonary disease. J Clin Invest 122: 2749-2755, 2012.

15. Yu L, Ma R, Wang Y and Nishino H: Potent anti-tumor activity and low toxicity of tubeimoside I isolated from Bolbostemma paniculatum. Planta Med 60: 204-208, 1994.

16. Wang CX, Ma RD and Yu LJ: Inhibitory effects of tubeimoside I, a cyclic bisdesmoside isolated from Bolbostemma paniculatum, on metastases of mouse B16 melonoma and lewis lung carcinoma. Chin J Clin Pharmacol Ther 11: 764, 2006.

17. Jia G, Wang Q, Wang R, Deng D, Xue L, Shao N, Zhang Y, Xia X, Zhi F and Yang Y: Tubeimoside-1 induces glioma apoptosis through regulation of $\mathrm{Bax} / \mathrm{Bcl}-2$ and the ROS/Cytochrome C/Caspase-3 pathway. Onco Targets Ther 8: 303-311, 2015. 
18. Li P, Xin J, Wang Y, Wang S, Li G, Pan X, Liu Z and Wang L: The acute effects of fine particles on respiratory mortality and morbidity in Beijing, 2004-2009. Environ Sci Pollut Res Int 20: 6433-6444, 2013.

19. Tsai SS, Chiu HF, Liou SH and Yang CY: Short-term effects of fine particulate air pollution on hospital admissions for respiratory diseases: A case-crossover study in a tropical city. J Toxicol Environ Health A 77: 1091-1101, 2014.

20. Strak M, Janssen NA, Godri KJ, Gosens I, Mudway IS, Cassee FR, Lebret E, Kelly FJ, Harrison RM, Brunekreef B, et al: Respiratory health effects of airborne particulate matter: The role of particle size, composition and oxidative potential-the RAPTES project. Environ Health Perspect 120: 1183-1189, 2012.

21. Hartz AM, Bauer B, Block ML, Hong JS and Miller DS: Diesel exhaust particles induce oxidative stress, proinflammatory signaling and P-glycoprotein up-regulation at the blood-brain barrier. FASEB J 22: 2723-2733, 2008.

22. Mutlu EA, Engen PA, Soberanes S, Urich D, Forsyth CB, Nigdelioglu R, Chiarella SE, Radigan KA, Gonzalez A, Jakate $\mathrm{S}$, et al: Particulate matter air pollution causes oxidant-mediated increase in gut permeability in mice. Part Fibre Toxic 8: 19, 2011.
23. Singh S, Grover V, Christie L, Charles P, Kelleher P and Shah PL: A comparative study of bronchoscopic microsample probe versus bronchoalveolar lavage in patients with burns-related inhalational injury, acute lung injury and chronic stable lung disease. Respiration 89: 19-26, 2015.

24. Romieu I, Garcia-Esteban R, Sunyer J, Rios C, Alcaraz-Zubeldia M, Velasco SR and Holguin F: The effect of supplementation with omega-3 polyunsaturated fatty acids on markers of oxidative stress in elderly exposed to PM (2.5). Environ Health Perspect 116: 1237-1242, 2008.

25. Qian H and Liu D: The time course of malondialdehyde production following impact injury to rat spinal cord as measured by microdialysis and high pressure liquid chromatography. Neurochem Res 22: 1231-1236, 1997.

26. Perez Y, Oyarzabal A, Mas R, Molina V and Jimenez S: Protective effect of D-002, a mixture of beeswax alcohols, against indomethacin-induced gastric ulcers and mechanism of action. J Nat Med 67: 182-189, 2013.

27. Snyder S and Bredt DS: Biological roles of nitric oxide. Sci Am 266: 68-71, 1992.

28. Virág L, Szabó E, Gergely P and Szabó C: Peroxynitrite-induced cytotoxicity: Mechanism and opportunities for intervention. Toxicol Lett: 113-124: 140-141, 2003. 